\title{
The Anti-Plasticization Effects of Dimethyl Carbonate Plasticizer in Poly (Methyl Metacrylate) Electrolyte Containing Rubber
}

\author{
Famiza Latif ${ }^{1}$, Madzlan Aziz $^{2}$ \\ ${ }^{1}$ Faculty of Applied Sciences, Universiti Teknologi MARA, Shah Alam, Malaysia; ${ }^{2}$ Department of Chemistry, Faculty of Science, \\ Universiti Teknologi Malaysia, Skudai, Malaysia. \\ Email: famiza@salam.uitm.edu.my
}

Received July $31^{\text {st }}, 2013$; revised September $2^{\text {nd }}, 2013$; accepted September $21^{\text {st }}, 2013$

Copyright (C) 2013 Famiza Latif, Madzlan Aziz. This is an open access article distributed under the Creative Commons Attribution License, which permits unrestricted use, distribution, and reproduction in any medium, provided the original work is properly cited.

\begin{abstract}
Various plasticizers have been used in polymer electrolyte systems, mainly to enhance the ionic conductivity of the electrolyte. Therefore, in this study, the effects of dimethyl carbonates, DMC plasticizer on the ionic conductivity of poly (methyl methacrylate), PMMA electrolyte film when blended with 50\% epoxidized natural rubber and ENR 50 were investigated. Unfortunately, the addition of DMC plasticizer reduced the ionic conductivity of this blend system at any amounts of plasticizer added. In addition, this DMC-plasticized system also exhibited higher activation energy than the unplasticized system. The effects of DMC plasticizer on the conductivity of this electrolyte system were investigated and explained using Field Emissions Scanning Electron Microscope, FESEM and Fourier Transform Infra Red, FTIR Spectrophotometer analyses. From these analyses, it can be concluded that the dielectric constant of a plasticizer is important when dealing with an electrolyte system containing rubber.
\end{abstract}

Keywords: Polymer Electrolytes; PMMA; ENR 50; DMC; Ionic Conductivity

\section{Introduction}

Plasticizer is defined as a relatively low molecular weight substance of low volatility, which, when added to another material, changes the physical and chemical properties of the material in such a manner that the finished product is in a more useful form [1]. In polymer electrolytes, plasticizers or mixed plasticizers are added to soften rigid polymers and to lower the glass transition temperature, $\mathrm{T}_{\mathrm{g}}$, of a polymer or polymer blend by increasing the segmental motion of the polymer backbone, hence assisting the transport of ions along the polymer chain. Furthermore, the addition of plasticizers helps to increase the dissolution of salts and dissociation of ion pairs and hence increase the number of free ions.

To date, there are several plasticizers that had been used as a plasticizer for the above mentioned purposes, such as ethylene carbonate (EC) [2], propylene carbonate (PC) [3], dimethyl carbonates (DMC) [4], dimethyl formamide (DMF) [5], etc. Amongst them, the most widelyused plasticizers are EC and PC, due to their low molecular weight, low viscosity, high dielectric constant and high boiling point properties.

However, not all plasticizers are found to be suitable in any polymer electrolyte system resulting in poor ionic conductivity. According to Bernardo and Burell [1], antiplasticization effects of plasticizer may occur in certain amount of plasticizer. This phenomenon exists in our previous work [6] in which the addition of EC reduced the ionic conductivity of PMMA/ENR $50 / \mathrm{LiCF}_{3} \mathrm{SO}_{3}$ from $10^{-6} \mathrm{~S} / \mathrm{cm}$ to $10^{-8} \mathrm{~S} / \mathrm{cm}$ at room temperature. In this EC plasticized system, we found that it was incompatible with epoxidised natural rubber in which it caused the rubber to be coagulated, hence reduced the ionic conductivity of the unplasticized system. The high dielectric constant of EC $(\varepsilon=95)$ may increase the number of "free" mobile ENR 50 chains resulting in chain entanglement hence leading to the formation of coagulates. Since ENR 50 was able to enhance the ionic conductivity $\left(10^{-5} \mathrm{~S} / \mathrm{cm}\right)$ [7] and improve the mechanical strength and adhesion properties of PMMA film electrolyte, it is important to further improve the ionic conductivity of the PMMA film since it was proven to exhibit good interfa- 
cial properties towards the lithium electrodes [8,9]. Therefore, DMC plasticizer that has much lower dielectric constant $(\varepsilon=3)$ than EC was chosen in this study to avoid the formation of excessive ENR 50 coagulation that hinders the migration of ions in the blend system. Though DMC also exhibited lower ionic conductivity than the unplasticized blend system, the phenomenon that occurred in this DMC plasticized system was not the same as in the EC plasticized system. To the best of our knowledge, DMC plasticizer may exhibit a high ionic conductivity of $10^{-3} \mathrm{~S} / \mathrm{cm}$ at room temperature in other PMMA-based electrolyte system [10] but not when ENR 50 was blended with it. Therefore, this work emphasized the factors that occurred in this kind of polymer blend system.

\section{Experimental}

\subsection{Film Preparation}

(ALDRICH) and dimethyl carbonate, DMC plasticizer (BDH) were used without further purification. ENR 50 was obtained from Guthrie Polymer Sdn. Bhd. Siliau, Negeri Sembilan, Malaysia. PMMA and ENR 50 stock solutions were prepared separately by dissolving the polymers in THF by continuous stirring with magnetic stirrer. Fixed volume of the two polymer solutions were then mixed in a beaker containing fixed amount of $\mathrm{LiCF}_{3} \mathrm{SO}_{3}$ salt. Various amounts of DMC plasticizer was added into the solution mixture. The mixtures were then stirred for about 24 hours. All the preparation steps were done in a glove box. The electrolyte solutions were then cast into glass petri dishes and left to dry by solvent evaporation at room temperature. The films obtained were further dried in an oven at $50^{\circ} \mathrm{C}$ for another 48 hours. The solvent free films were then kept in a desiccator until further use.

\subsection{Material Characterizations}

The morphology of the films was investigated under LEO Field Emissions Scanning Electron Microscope. The FTIR spectra of the thin films was obtained from SHIMADZU FTIR 8300 Fourier Transform Infra Red Spectrophotometer in the frequency range of $4000-400$ $\mathrm{cm}^{-1}$. The conductivity measurement was performed by Hioki 3532 - 50 LCR HiTester Impedance Spectroscopy over a frequency range of $100 \mathrm{~Hz}$ to $1 \mathrm{MHz}$ from room to $359 \mathrm{~K}$.

\section{Results and Discussions}

All DMC plasticized PMMA/ENR 50/ $\mathrm{LiCF}_{3} \mathrm{SO}_{3}$ electrolyte films were transparent and stable at room temperature. Interestingly, though the phase separation can still be observed on the surface of the films, it was almost diminishing and insignificant.

\subsection{FESEM Studies on the Morphology of Plasticized PMMA/ENR 50/LiCF $\mathrm{SO}_{3}$ Films}

From observation, as the volume of DMC plasticizer increased, the film became congested (Figure 1(b)) with dissolved lithium salt that spread in the entire volume of the blend hence reduced the gap between the PMMA and the ENR 50 phase. This may explain why at higher volume of DMC plasticizer, the two phases became almost invisible and a physically better appearance of the blend film was obtained. Large craters were formed in the SEM micrographs of the blend when DMC plasticizer was added (Figure 1). The formation of craters were also

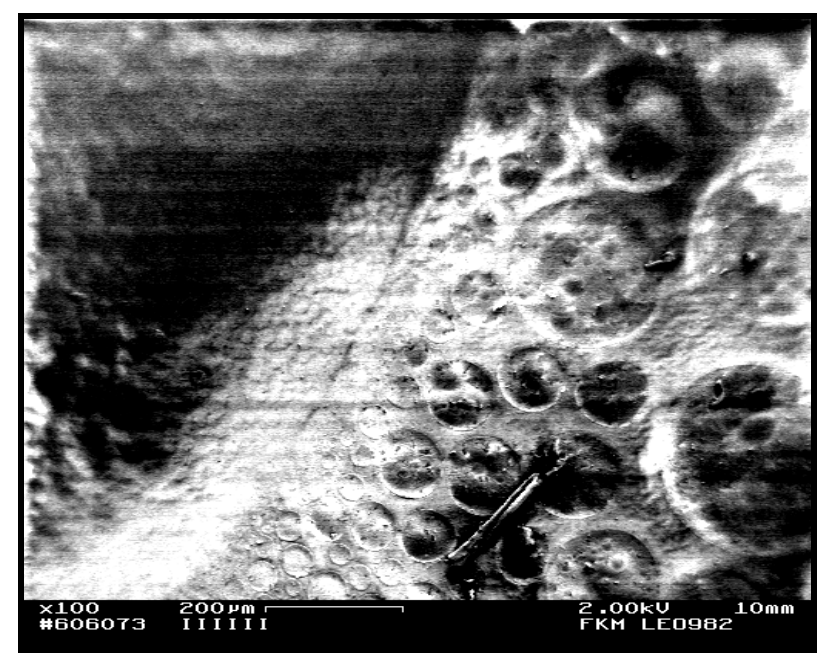

(a)

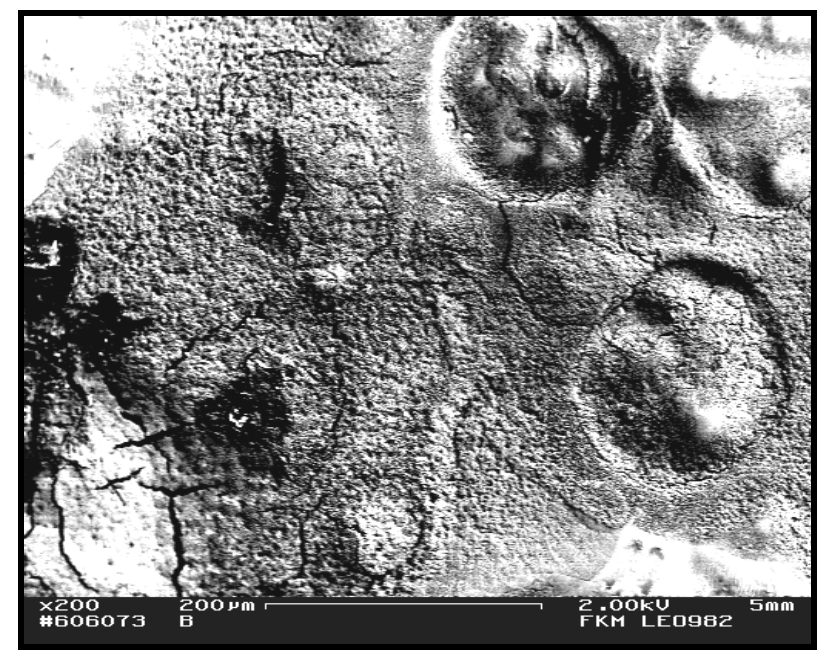

(b)

Figure 1. FESEM micrographs for PMMA/ENR 50/LiCF $\mathrm{SO}_{3}$ films when plasticized with (a) $1 \mathrm{ml}$ and (b) $3 \mathrm{ml}$ of DMC plasticizer. 
observed in the un-doped blend [6] when ENR 50 suppressed the globular structures of PMMA [6] as it penetrated the PMMA phase. The larger craters that were formed in these plasticized blends support the increment in the polymers chains flexibility that allows them to merge into each other's phase. Therefore, more globular structures of PMMA were suppressed by ENR 50.

\subsection{FTIR Analysis on Plasticized PMMA/ENR 50/LiCF $\mathrm{SO}_{3}$ Electrolytes}

It was found that the intensity of the $-\mathrm{OH}$ band at $\sim 3500$ (Figure 2) that relates to the occurrence of H-bonding have been reduced in the presence of plasticizer indicating a reduction in the number of interchain crosslinking between the two polymers. This confirmed that the addition of plasticizer increased the polymers chains flexibility.

It was found that the intensity of $\mathrm{V}_{\mathrm{s}}\left(\mathrm{CF}_{3}\right)$ and $\mathrm{V}_{\mathrm{s}}\left(\mathrm{SO}_{3}\right)$ at $\sim 1350 \mathrm{~cm}^{-1}$ and $\sim 1033 \mathrm{~cm}^{-1}$ peaks were reduced when DMC plasticizer was added into the system (Figure 3) indicating a marked reduction in the number of free ions due to the formation of ion pair or ion aggregates as a result of ion congestions. Therefore, there was no significant shifting and change in the intensity of the carbonyl peak of PMMA at $\sim 1720 \mathrm{~cm}^{-1}$ (Figure 3) as the amount of DMC plasticizer was increased hence suggesting that no further complexation that occurred between the polymer and the salt.

The reduction in the intensity of the epoxy band of ENR 50 at $\sim 1250 \mathrm{~cm}^{-1}$ and $\sim 838 \mathrm{~cm}^{-1}$ (Figure 3) and the disappearance of the carbonate band of the plasticizer at $\sim 1759 \mathrm{~cm}^{-1}$ (Figure 3) may suggest the occurrence of polymer-plasticizer interaction via polar linkages [6] due to its affinity towards ENR 50. However, this polar

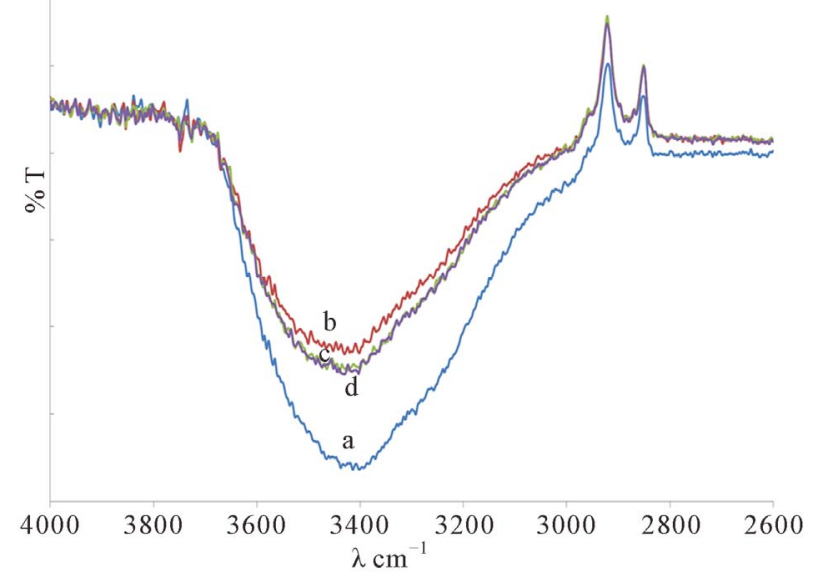

Figure 2. The FTIR spectra of the -OH band for PMMA/ ENR 50/ $\mathrm{LiCF}_{3} \mathrm{SO}_{3}$ Films when plasticized with (a) $0 \mathrm{ml}$, (b) $1 \mathrm{ml}$, (c) $2 \mathrm{ml}$ and (d) $3 \mathrm{ml}$ of DMC.

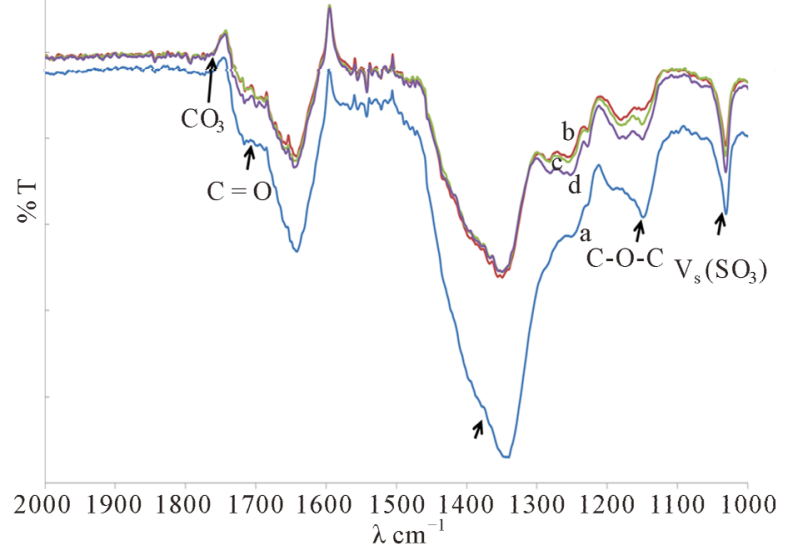

Figure 3. The FTIR spectra of various bands in PMMA/ ENR 50/ $/ \mathrm{LiCF}_{3} \mathrm{SO}_{3}$ Films when plasticized with (a) $0 \mathrm{ml}$, (b) $1 \mathrm{ml}$, (c) $2 \mathrm{ml}$ and (d) $3 \mathrm{ml}$ of DMC.

linkages are weaker than the inter-or intra molecular hydrogen bonding.

\subsection{Ionic Conductivity Studies on Plasticized PMMA/ENR 50/LiCF $\mathrm{SO}_{3}$ Electrolytes}

Table 1 summarized the ionic conductivity of these plasticized PMMA/ENR 50/ $\mathrm{LiCF}_{3} \mathrm{SO}_{3}$ electrolyte systems. The data obtained in Table 1 supports the results obtained in the FTIR analyses where the conductivity obtained for the plasticized systems is lower than the unplasticized system due to the lower number of the charge carrier due to the formation of ion congestion that was observed in the SEM micrograph of the plasticized system at higher amount of plasticizer. The presence of craters may also trap the lithium ion in its vicinity hence hindering the migration of ion. These may also explain why the activation energies, Ea obtained from these plasticized systems are slightly larger than the un-plasticized system (Table 1).

Though various factors contribute to the lower ionic conductivity of this DMC plasticized PMMA/ENR 50 $\mathrm{LiCF}_{3} \mathrm{SO}_{3}$ system, it is still slightly higher than the EC plasticized system $\left(3.84 \times 10^{-7} \mathrm{~S} / \mathrm{cm}\right)[6]$ due to no large coagulate structures were formed in the system.

Since the regression, $\mathrm{r}^{2}$ value for all the plots of $\ln (\sigma)$ versus 1000/T (Figure 4) for these plasticized system lie in the range of 0.96 to 0.999 , therefore, it can be considered that the points were almost in a straight line. This implies that the conductivity behaviour of this system as a function of temperature can be fitted by the Arrhenius law in which the ion transport was similar to that in ionic crystals.

\section{Conclusion}

The addition of DMC plasticizer in PMMA/ENR 50/ 
Table 1. The average conductivity of PMMA/ENR 50/ $\mathrm{LiCF}_{3} \mathrm{SO}_{3} / \mathrm{DMC}$ electrolytes at various amounts of DMC and temperatures.

\begin{tabular}{ccccccccc}
\hline & \multicolumn{9}{c}{ Conductivity, $\sigma \times 10^{-7} \mathrm{~S} / \mathrm{cm}$} & \multicolumn{1}{c}{$E_{a}$} \\
$\left(\times 10^{-1} \mathrm{eV}\right)$
\end{tabular}

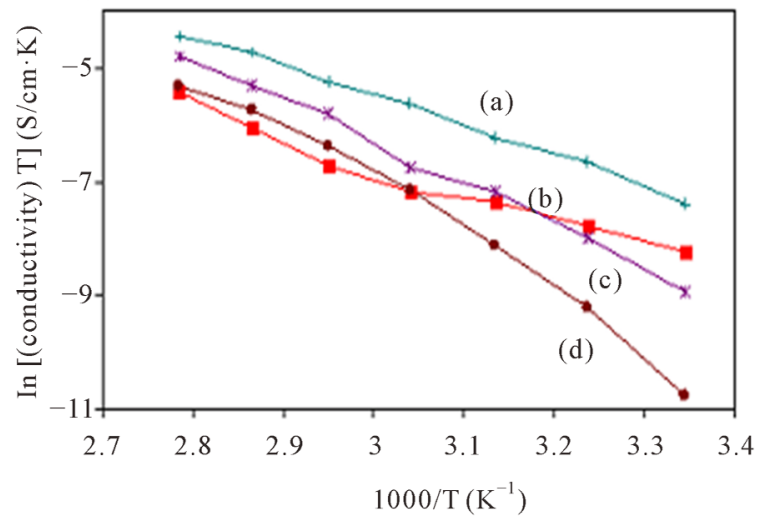

Figure 4. Arrhenius plot for PMMA/ENR $50 / \mathrm{LiCF}_{3} \mathrm{SO}_{3}$ electrolyte when plasticized with (a) $0 \mathrm{ml}$ [11], (b) $1 \mathrm{ml}$, (c) 2 $\mathrm{ml}$ and (d) $3 \mathrm{ml}$ of DMC.

$\mathrm{LiCF}_{3} \mathrm{SO}_{3}$ was found to reduce the ionic conductivity of the unplasticized electrolyte because it contained lower number of charge carrier due to the formation of ion pairs and ion aggregates or trapping of charge in the vicinity of the craters. Therefore, it can be concluded that the value of dielectric constant of a plasticizer is important when dealing with polymer electrolyte system containing ENR 50.

\section{Acknowledgements}

Financial support from IRPA, FRGS grants and technical support from Universiti Teknologi MARA are highly acknowledged. Thanks to Guthrie Polymer Sdn. Bhd. Siliau, Negeri Sembilan, Malaysia for providing free samples of ENR 50.

\section{REFERENCES}

[1] J. J. Bernardo and H. Burell, "Plasticization," In: A. D.
Jenkins, Ed., Polymer Science, North Holland Publishing Company, Holland, 1972, pp. 538-578.

[2] S. A. M. Noor, A. Ahmad, I. A. Talib and M. Y. A. Rahman, "Morphology, Chemical Interaction, and Conductivity of a PEO-ENR50 Based on Solid Polymer Electrolyte," Ionics, Vol. 16, No. 2, 2010, pp. 161-170. http://dx.doi.org/10.1007/s11581-009-0385-6

[3] S. Boor, M. S. Hundal, G. G. Park, J. S. Park, W. Y. Lee, C. S. Kim, K. Yamada and S. S. Sekhon, "Non-Aqueous Polymer Electrolytes Containing Room Temperature Ionic Liquid: 2,3-Dimethyl-1-octylimidazolium Tetrafluoroborate," Solid State Ionics, Vol. 178, No. 23-24, 2007, pp. 1404-1410. http://dx.doi.org/10.1016/j.ssi.2007.08.001

[4] Y. K. Yarovoy, H. P. Wang and S. L. Wunder, "Dynamic Mechanical Spectroscopy and Conductivity Studies of Gel Electrolytes Based on Stereocomplexed Poly(methyl methacrylate)," Solid State Ionics, Vol. 118, No. 3-4, 1999, pp. 301-310. http://dx.doi.org/10.1016/S0167-2738(98)00442-1

[5] S. S. Sekhon, N. Arora and S. Chandra, "Proton Conducting Polymer Gel Electrolytes with $\mathrm{NO}_{2}$ Substituted Carboxylic Acids," European Polymer Journal, Vol. 39, No. 5, 2003, pp. 915-920. http://dx.doi.org/10.1016/S0014-3057(02)00358-0

[6] L. Famiza, A. Madzlan, A. A. M. Malik and M. Z. A. Yahya, "The Coagulation Impact of 50\% Epoxidised Natural Rubber Chain in Ethylene Carbonate-Plasticized Solid Electrolyte," Macromolecular Symposia, Vol. 277, No. 1, 2009, pp. 62-68. http://dx.doi.org/10.1002/masy.200950308

[7] L. Famiza, A. Madzlan, K. Nasir, A. A. M. Malik and M. Z. A. Yahya, "The Role and Impact of Rubber in Poly(methyl methacrylate)/lithium Triflate Electrolyte," Journal of Power Sources, Vol. 159, No. 2, 2006, pp. 1401-1404. http://dx.doi.org/10.1016/j.jpowsour.2005.12.007

[8] G. B. Appetecchi, F. Croce and B. Scrosati, "Kinetics and Stability of the Lithium Electrode in Poly(methyl methacrylate)-Based Gel Electrolytes," Electrochimica Acta, Vol. 40, No. 8, 1995, pp. 991-997. http://dx.doi.org/10.1016/0013-4686(94)00345-2

[9] K. M. Abraham and M. Alamgir, "Li ${ }^{+}$Conductive Solid Polymer Electrolytes with Liquid-Like Conductivity," Journal of Electrochemical Society, Vol. 137, No. 5, 1990, pp. 1657-1658. http://dx.doi.org/10.1149/1.2086749

[10] X. Hou and K. S. Siow, "Novel Interpenetrating Polymer Network Electrolytes," Polymer, Vol. 42, No. 9, 2001, pp. 4181-4188. http://dx.doi.org/10.1016/S0032-3861(00)00818-1

[11] P. Ghersa, "Effect of Small Quantities of Plasticizers in PVC Compounds," Modern Plastics, Vol. 36, No. 2, 1958, pp. $135-142$. 